\title{
Editorial
}

Onkologe $2020 \cdot 26: 676$

https://doi.org/10.1007/s00761-020-00819-1

(c) Springer Medizin Verlag $\mathrm{GmbH}$, ein Teil von Springer Nature 2020

\author{
Klaus Höffken ${ }^{1} \cdot$ Heinz Schmidberger ${ }^{2}$. Verena Stratmann ${ }^{3}$ \\ 'Berlin, Deutschland \\ ${ }^{2}$ Klinik und Poliklinik für Radioonkologie, Universitätsmedizin Mainz, Mainz, Deutschland \\ ${ }^{3}$ Springer Medizin Verlag GmbH, Heidelberg, Deutschland
}

\section{Wer ständig glücklich sein möchte, muss sich oft verändern}

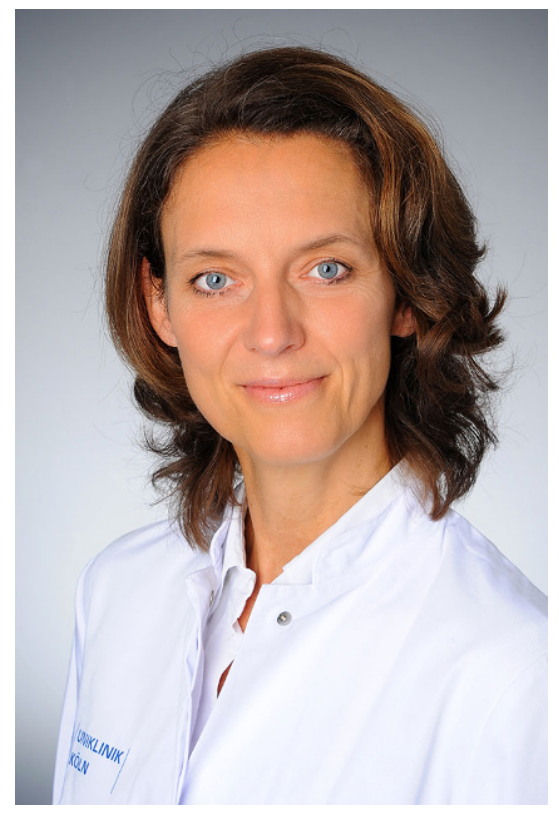

Abb. $1 \Delta$ Prof. Dr. Christiane Bruns

Mit diesem Zitat von Konfuzius möchten Herausgeber und Verlag Frau Professorin Dr. Christiane Bruns (• Abb. 1) als Vertreterin der onkologischen Chirurgie und neue Herausgeberin begrüßen. Sie tritt an die Stelle von Herrn Professor Schlag, dem wir in unserem vorigen Editorial in dieser Ausgabe unseren Respekt zollen.

Christiane Bruns ist seit 2016 Direktorin der Klinik und Poliklinik für Allgemein-, Viszeral-, Tumor- und Transplantationschirurgie und Vizedirektorin des Centrums für Integrierte Onkologie. Der Zeitschrift Der Onkologe ist Frau Prof. Bruns bereits seit einigen Jahren als Rubrikherausgeberin in der Rubrik Journal Club verbunden.

Der Wechsel geschieht in der Erkenntnis, dass man die Zukunftsfähigkeit eines Konzepts durch regelmäßige
Erneuerungen sichert. Damit Wandel mit Kontinuität die zukünftige Gestaltung „unserer“ Zeitschrift prägt, freuen wir uns, als die beiden weiter in der Verantwortung für Qualität und Aktualität der Fachzeitschrift stehenden Mitherausgeber, auf die gemeinsame Arbeit mit der neuen Mitherausgeberin, Frau Kollegin Christiane Bruns, und werden gemeinsam weiter unser Bestes geben, damit die Leserschaft von Der Onkologe im konfuzianischen Sinne ständig glücklich sein möge.

Für die Herausgeber Prof. Dr. Klaus Höffken

Prof. Dr. Heinz Schmidberger

Für den Verlag

Verena Stratmann

\section{Korrespondenzadresse}

\section{Verena Stratmann}

Springer Medizin Verlag GmbH

Tiergartenstr. 17, 69121 Heidelberg,

Deutschland

verena.stratmann@springer.com

Interessenkonflikt. K. Höffken, H. Schmidberger und $V$. Stratmann geben an, dass kein Interessenkonflikt besteht. 